Jurnal Sulolipu : Media Komunikasi Sivitas Akademika dan Masyarakat

Vol. 20 No.12020

e-issn : 2622-6960, p-issn : 0854-624X

\title{
"STUDI SANITASI LINGKUNGAN DENGAN KEPADATAN LALAT PADA PELELANGAN IKAN BEBA DI DESA TAMASAJU KECAMATAN GALESONG UTARA KABUPATEN TAKALAR"
}

\author{
Syahrul Rahmadana', La Taha² \\ 1,2Poltekkes Kemenkes Makassar Jurusan Kesehatan
}

(Syahrulrahmadana09@gmail.com)

\begin{abstract}
Fish Auction Place abbreviated as TPI is a market that is usually located in fish landing ports/bases, and in these places, there are fish/marine product sales transactions either by auction or not. The type of this research is observational using a descriptive approach, namely measuring the density of flies in the Beba fish auction area in Tamasaju village, Galesong sub-district, North Takalar district. The results of the research have been carried out by measuring the density of flies in sewerage (SPAL), which is 17 birds/block grafts while in the garbage disposal site (TPS) that is 10 tails/block grafts and in clean water facilities at the fish auction that is 8 tails / Flygrill. Based on the results of the research that has been done, it can be concluded that the density of flies at the fish auction is included in the solid category. therefore, the sellers at the fish auction in Suggest should pay more attention to the cleanliness and the environment around the fish auction by not disposing of the waste of fish waste in any place so that it is not a breeding place for flies.
\end{abstract}

Keywords: Flies Density Level, Beba Fish Auction, SPAL, TPS, Clean Water.

ABSTRAK

Tempat Pelelangan Ikan (TPI) merupakan pasar yang biasanya terletak di dalam pelabuhan/pangkalan pendaratan ikan, dan di tempat tersebut Terjadi transaksi penjualan ikan/hasil laut baik secara lelang maupun tidak. Jenis penelitian ini yaitu menggunakan observasional dengan pendekatakatan deskriptif yaitu melakukan pengukuran kepadatan lalat pada kawasan pelelangan ikan beba di desa tamasaju kecamatan galesong utara kabupaten takalar.Tujuan penelitian ini adalah untuk mengetahui studi sanitasi lingkungan dengan kepadatan lalat pada pelelangan ikan beba di desa tamasaju kecamatan galesong utara kabupaten takalar. Hasil penelitian yang telah dilakukan dengan pengukuran kepadatan lalat pada saluran air limbah (SPAL) yaitu 17 ekor/Flykgrill sedangkan pada tempat pembuang sampah (TPS) yaitu 10 ekor/Flygrill dan pada sarana air bersih pada pelelangan ikan yaitu 8 ekor/Flygrill. Berdasarkan hasil penelitian yang telah dilakukan didapatkan kesimpulan bahwa tingkat kepadatan lalat pada pelelangan ikan termasuk dalam kategori padat.oleh karna itu para penjual di pelelangan ikan di Sarankan harus lebih memperhatikan kebersihan dan lingkungan disekitar pelelangan ikan dengan tidak membuang sampah ampas ikan disembarang tempat sehingga tidak menjadi tempat perkembangbiakan oleh lalat.

Kata Kunci : Tingkat Kepadatan Lalat, Pelelangan Ikan Beba, SPAL, TPS, Air Bersih.

\section{PENDAHULUAN}

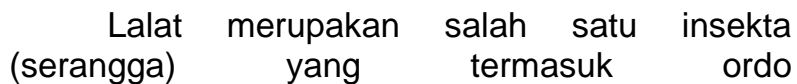
diphtera,mempunyai sepasang sayap berbentuk membran. Lalat juga merupakan speciesyang berperan dalam masalah kesehatan masyarakat, yaitu sebagai vektorpenularan penyakit saluran pencernaan seperti: Diare , kolera, typhus, disentri, dan lain lain.Pada saat ini dijumpai \pm 60.000 - 100.000 spesies lalat, tetapi tidak semuaspecies perlu diawasi karena beberapa diantaranya tidak berbahaya terhadapkesehatan masyarakat.Penularan penyakit dapat terjadi melalui semua bagian dari tubuh lalatseperti : bulu badan, bulu pada anggota gerak, muntahan serta faecesnya (Manggoli, dkk, 2016).

Penyakit diare merupakan penyakit endemis di Indonesia dan juga merupakan penyakit potensial KLB yang sering disertai dengan kematian. Pada tahun 2013 terjadi 8 KLB yang tersebar di 6 Propinsi, 8 kabupaten dengan jumlah penderita 646 orang dengan kematian 7 orang (CFR 1,08\%). Sedangkan pada tahun 2014 terjadi KLB Diare yang tersebar di 5 propinsi, 6 kabupaten/kota, dengan jumlah penderita 2.549 orang dengan kematian 29 orang (CFR 1,14\%)..(Profil Kesehatan .2014). Kabupaten/Kota dengan angka kesakitan diare tertinggi (13.68928.908) yaitu Kabupaten Makassar, Gowa, Bulukumba, Takalar, Pangkep, dan Luwu Utara, sedangkan terendah (2,679-6.398) yaitu Kabupaten Selayar, Sinjai, Maros, Barru, Luwu, Tana Toraja, dan Kota Parepare.

Pentingnya pengukuran kepadatan lalat sebagai suatu alasan untuk mengetahui tingkat kepadatanya. Berdasarkan Keputusan Menteri Kesehatan Republik Indonesia 1405/Menkes/SK/IX/2002 tentang persyaratan kesehatan lingkungan kerja mengatur bahwa: "untuk persyaratan indeks lalat maksimal 8 ekor/fly grill $(100 \times 100 \mathrm{~cm})$ dalam pengukuran 30 menit sehingga jika ditemukan lebih dari itu perlu adanya pengendalian (Kepmen 1405/Menkes/SK/IX, 2002).

Berdasarkan data Dinas kesehatan Provinsi Sulawesi selatan tahun 2014 dinyatakan bahwa 243,669 Kasus kejadian penyakit diare yang ada di wilayah puskesmas Provinsi Sulawesi selatan , dan jumlah kasus penyakit diare yang ada di 
Jurnal Sulolipu : Media Komunikasi Sivitas Akademika dan Masyarakat

Vol. 20 No.12020

e-issn : 2622-6960, p-issn : 0854-624X

kabupaten Pangkajene kepulauan adalah 7,635 Kasus .( Dinkes Sulawesi selatan .2014).

Melihat kondisi kawasan pelelangan ikan yang ada di takalar khususnya yang terletak di pantai beba desa tamasaju Kec.Galesong utara kab.Takalar, sangat strategis untuk para nelayan untuk menjual ikan hasil tangkapannya. Selain tempatnya yang strategis banyaknya penjual ikan yang tidak memperhatikan kondisi lingkungan sehingga banyak sampah yang berserakan dan air limbah pencucian ikan yang banyak mengundang lalat yang bisa menimbulkan banyak penyakit untuk masyarakat setempat. Untuk itu masyarakat dihimbau untuk menjaga lingkungannya agar tetap bersih sehingga dapat meminimalisir penyakit yang di akibatkan oleh lalat.

Penelitian yang dilakukan oleh Lestari (2014) kepadatan lalat pada ikan basah di pasar Pannampu kota Makassar dengan hasil pengukuran kepadatan lalat rata-rata 7 ekor Lalat dengan suhu $33^{\circ} \mathrm{C}$ dan kelembaban $62 \%$.

\section{METODE PENELITIAN}

1. Lokasi Penelitian

Adapun lokasi penelitian ini bertempat pada kawasan pelelangan ikan beba di Desa tamasaju kec. Galesong utara kab.Takalar.

2. Variabel Penelitian

Berdasarkan kerangka konsepsional, maka variabel yang akan di teliti dapat di lihat pada skema hubungan variabel berikut ini:

\section{TEKNIK PENGUMPULAN DATA}

\section{Data Primer}

Data primer diperoleh dari hasil pengukuran kepadatan lalat dan hasil pengamatan.

2. Data Sekunder

Data sekunder diperoleh dari hasil penelusuran perpustakaan berupa buku - buku yang berkaitan dengan penelitian, hasil penelitan sebelumnya serta internet dan media informasi lainnya.

3. Teknik Analisa Data

Hasil pengamatan dan pengukuran lapangan disajikan dalam bentuk tabel,kemudian dianalisa secara deskriktif untuk mengetahui hasil dan variabel yang akan diteliti,maka hasil sampel dari tingkat pengukura lalat dibandikan dengan standar yang ditetapkan.

HASIL PENELITIAN

adapun hasil yang diperoleh sebagai berikut:

1. Distribusi kepadatan lalat pada saluran pembuangan air limbah (SPAL) pada pelelangan ikan beba di desa tamasaju kecamatan galesong utara kabupaten takalar.

Tabel 1

Rata-Rata Kepadatan Lalat, Suhu Dan Kelembaban Pada SPAL di Lokasi Pelelangan Ikan Beba kabupaten Takalar

\begin{tabular}{|c|c|c|c|}
\hline \multirow{2}{*}{ Titik } & \multicolumn{3}{|c|}{ Hasil Pengukuan } \\
\cline { 2 - 4 } & $\begin{array}{c}\text { Rata-rata } \\
\text { Kepadatan } \\
\text { lalat }\end{array}$ & Suhu $\left({ }^{\circ} \mathrm{C}\right)$ & $\begin{array}{c}\text { Kelembaban } \\
(\%)\end{array}$ \\
\hline Titik I & 13 & 40,3 & 50 \\
\hline Titik II & 16 & 40,3 & 50 \\
\hline Titik III & 15 & 40,3 & 50 \\
\hline Titik IV & 17 & 40,3 & 50 \\
\hline Titik V & 21 & 40,3 & 50 \\
\hline Titik VI & 18 & 40,3 & 50 \\
\hline Titik VII & 16 & 40,3 & 50 \\
\hline Titik VIII & 16 & 40,3 & 50 \\
\hline Titik IX & 18 & 40,3 & 50 \\
\hline Titik X & 15 & 40,3 & 50 \\
\hline Rata-rata & 17 & 40,3 & 50 \\
\hline
\end{tabular}

Dari tabel 1 dapat di lihat bahwa hasil pengukuran jumlah kepadatan lalat di lokasi pelelangan ikan beba kabupaten takalar dengan hasil rata-rata 17 ekor lalat/Flygrill dengan suhu rata-rata $40,3\left({ }^{\circ} \mathrm{C}\right)$ kelembaban $50 \%$

2. Distribusi kepadatan lalat pada tempat pembuangan sampah (TPS) di pelelangan ikan beba di desa tamasaju kecamatan galesong utara kabupaten takalar. 
Jurnal Sulolipu : Media Komunikasi Sivitas Akademika dan Masyarakat

Vol. 20 No.12020

e-issn : 2622-6960, p-issn : 0854-624X

Tabel 2

Rata-rata kepadatan lalat, suhu dan kelembaban pada tempat pembuangan sampah (TPS) dilokasi pelelangan ikan beba kabupaten takalar

\begin{tabular}{|c|c|c|c|}
\hline \multirow{2}{*}{$\begin{array}{c}\text { Titik } \\
\text { Pengukuran }\end{array}$} & \multicolumn{3}{|c|}{ Hasil Pengukuan } \\
\cline { 2 - 4 } & $\begin{array}{c}\text { Kepadatan } \\
\text { lalat }\end{array}$ & $\begin{array}{c}\text { Suhu } \\
\left.\mathbf{}^{\circ} \mathrm{C}\right)\end{array}$ & $\begin{array}{c}\text { Kelembaban } \\
(\%)\end{array}$ \\
\hline Titik I & 13 & 33 & 64 \\
\hline Titik II & 12 & 33 & 64 \\
\hline Titik III & 12 & 33 & 64 \\
\hline Titik IV & 10 & 33 & 64 \\
\hline Titik V & 8 & 33 & 64 \\
\hline Titik VI & 8 & 33 & 64 \\
\hline Titik VII & 11 & 33 & 64 \\
\hline Titik VIII & 5 & 33 & 64 \\
\hline Titik IX & 7 & 33 & 64 \\
\hline Titik X & 7 & 33 & 64 \\
\hline Rata-rata & 10 & 33 & 64 \\
\hline
\end{tabular}

3. Distribusi kepadatan lalat pada wadah air bersih di pelelangan ikan beba di desa tamasaju kecamatan galesong utara kabupaten takalar.

Tabel 3

Rata-rata kepadatan lalat, suhu dan kelembaban pada wadah air bersih dilokasi pelelangan ikan beba kabupaten Takalar

\begin{tabular}{|c|c|c|c|}
\hline Titik & \multicolumn{3}{|c|}{ Hasil Pengukuan } \\
\hline Pengukuran & $\begin{array}{c}\text { Kepadatan } \\
\text { lalat }\end{array}$ & $\begin{array}{c}\text { Suhu } \\
\left({ }^{\circ} \mathrm{C}\right)\end{array}$ & $\begin{array}{c}\text { Kelembaban } \\
(\%)\end{array}$ \\
\hline Titik I & 8 & 32,3 & 68 \\
\hline Titik II & 9 & 32,3 & 68 \\
\hline Titik III & 7 & 32,3 & 68 \\
\hline Titik IV & 6 & 32,3 & 68 \\
\hline Titik V & 7 & 32,3 & 68 \\
\hline Titik VI & 7 & 32,3 & 68 \\
\hline Titik VII & 8 & 32,3 & 68 \\
\hline Titik VIII & 7 & 32,3 & 68 \\
\hline Titik IX & 8 & 32,3 & 68 \\
\hline Titik X & 8 & 32,3 & 68 \\
\hline Rata-rata & 8 & 32,3 & 68 \\
\hline
\end{tabular}

\section{PEMBAHASAN}

Berdasarkan hasil pengukuran tingkat kepadatan lalat di Tempat Pelelangan Ikan Beba ditinjau dari SPAL pada tabel 5.1 dengan rata-rata 17 ekor/blokgrill dengan suhu 43,3 kelembaban $50 \%$, padat di jumpai pada saluran air limbah tersebut terbuka, tergenang air dan banyak terdapat sampah organik berupa sisa-sisa makanan ,pembungkus makanan serta ampas ikan yang di buang, pengukuran di lokasi tersebut merupakan rata-rata pengukuran tertinggi dibandingkan di TPS, tempat sampah, dan air bersih, salah satu faktor yang mempengaruhi karena kondisi SPAL (Saluran Pembuangan Air Limbah) di pelelangan ikan beba Takalar langsung merembes ke tanah tanpa adanya saluran drainase yang memenuhi syarat, sehingga lingkungan disekitar lokasi tersebut Nampak sangat kumuh, dimana antara SPAL dan Pembuangan sampah di lokasi tersebut tidak dapat dibedakan antara tempat pembuangan sampah dengan saluran pembuangan limbah, hal ini dikarenakan sampah dan saluran air limbah menyatu di lokasi tersebut dalam artian, pedagang atau masyarakat di tempat tersebut hanya membuang sampahnya disembarangan tempat baik itu di lokasi aliran air limbah ataupun di pinggiran laut, sehingga tidak dapat dibedakan antara saluran air limbah dan tempat sampah, Aktivitas pelelangan ikan membawadampak pencemaran bagi lingkungan dan kesehatan masyarakat sekitar. Dampak pencemaran tersebut dilihat dari 3 aspek. Aspek pertama yaitu aspek fisik, yaitu berupa air limbah cair dan limbah padat hasil pelelangan ikan yang menimbulkan bau tidak sedap. Aspek kedua yaitu aspek kimia yang berpotensi mencemari lingkungan. Aspek ketiga yaitu aspek biologi, yaitu adanya timbulan sampah terutama limbah padat menjadi tempat perindukan lalat.(Sitobang, 2013).

Salah satu faktor kumuhnya lokasi pelelangan ikan beba dikarenakan tidak terdapat atau tidak tersedianya wadah tempat sampah di lokasi tersebut, sehingga sampah berserakan di mana-mana, salah satu sampah terbanyak yang dihasilkann dilokasi tersebut adalah sampah plastik dari pedagang, kardus-kardus, serta sampah sisa-sisa makanan, dan TPS di lokasi tersebut juga tidak tersedia dalam artian berupa bak Kontainer yang memenuhi syarat, baik Tempat Pembuangan Sampah Sementara (TPS) tidak tersedia dilokasi tersebut, hal ini dikarenakan tidak adanya pengelolaan sampah dilokasi tersebut, selain hal itu kurangnya perhatian dari pemerintah setempat sehingga pasar yang 
Jurnal Sulolipu : Media Komunikasi Sivitas Akademika dan Masyarakat

Vol. 20 No.12020

e-issn : 2622-6960, p-issn : 0854-624X

dijadikan nelayan sebagai tempat mata pencaharian masyarakat sekitar sangat tidak layak, selain lokasi tersebut tidak memenuhi syarat untuk dijadikan tempat jual beli juga dapat mendatangkan penyakit sewaktu-waktu karena lingkungan yang hampir sama dengan lingkungan di TPA (Tempat Pembuangan Akhir) yang dipenuhi dengan sampah.

Tabel 5.2 dengan rata-rata 10 ekor/Flygrill suhu $33^{\circ} \mathrm{C}$ kelembaban $64 \%$, dan sarana air bersih pada Tabel 5.3 dengan rata-rata 8 ekor/blokgrill suhu $32,3^{\circ} \mathrm{C}$ kelembaban $68 \%$ hal ini kategori sangat padat berdasarkan Permenkes No.50 Tahun 2017 tentang standard baku mutu kesehatan lingkungan dan persyaratan kesehatan untuk vektor dan binatang pembawa penyakit dalam hal ini $<2$ ekor/blokgrill. Penelitian yang dilakukan oleh Lestari (2014) kepadatan lalat pada ikan basah di pasar Pannampu kota Makassar dengan hasil pengukuran kepadatan lalat rata-rata 7 ekor Lalat dengan suhu $33^{\circ} \mathrm{C}$ dan kelembaban $62 \%$. Kepadatan lalat di lokasi sumber air bersih yang dijadikan masyarakat sekitar atau pedagang di sekitar pelelangan ikan termasuk kategori tidak memenuhi syarat karena melebihi baku mutu vector, salah satu hal yang mempengaruhi karena lokasi sumber air bersih di pelelangan ikan beba Takalar dekat dengan sumber-sumber yang disukai oleh lalat yaitu dekat dengan warung makan, di mana warung makan di lokasi tersebut dilihat kondisinya yang becek, dan masih terdapat sampah disekitar warung tersebut, dan terlihat jelas lalat berkerumun. Sesuai dengan teori yang ada bahwapenularan terjadi karna kontak lalat dengan manusia atau makananya. Beberapa penyakit yang ditularkan melalui kontaminasi makanan, air, udara, tangan dan kontak antara orang dengan orang (sucipto, et.all 2011).

Adapun penyebab tingginya tingkat kepadatan lalat diantaranya adalah banyaknya sampah berserakan, bau yang tidak sedap, dan tempat tersebut merupakan tempat berkembang biak bagi lalat karena mendapatkan sumber makanan di tempat-tempat yang kotor, becek dan kumuh di mana Kondisi lingkungan di Tempat Pelelangan Ikan Beba berdasarkan pengamatan yang dilakukan jorok dan sangat kumuh, untuk itu perlunya dilakukan perbaikan sanitasi lingkungan di lokasi tersebut.

Masalah kesehatan berkaitan dengan populasi lalat umumnya berhubungan dengan unit pelelangan, peternakan dan tempat pembuangan sampah. Seperti yang telah diketahui bahwa lalat merupakan jenis serangga yang mempunyai kemampuan terbang hingga jarak $8 \mathrm{~km}$. Dengan demikian tempat pelelangan ikan dalam radius tersebut sangat rawan terhadap tingkat kepadatan lalat yang tinggi. Kepadatan lalat akan meningkat jika lingkungan disekitarnya memungkinkan untuk menjadi tempat perindukan lalat, (Sitobang, 2013).

Adapun jenis lalat yang terdapat di tempat pelelangan ikan beba Takalar yaitu rata-rata lalat jenis Musca Domestika (lalat rumah), Ada ciri - ciri yang penting dari lalat ini yaitu pada torakx terdapat empat garis hitam dan satu garis hitam medial pada abdomen dorsal. Sayapnya mempunyai longitudinal line 4 yang yang jalannya menaik keatas, sehingga hampir bertemu dengan long 3. Bagian - bagian dari mulut tidak dapat dipakai untuk menggigit atau menusuk, tetapi hanya dapat dipakai menghisap barang - barang cair. Serangga ini memiliki metamorphosis sempurna dan berperan sebagai vektor dari penyakit tidak langsung.Lalat juga merupakan spesies yang berperan dalam masalah kesehatan masyarakat, yaitu sebagai vektor penularan penyakit saluran pencernaan seperti: kolera, thypus, disentri dan lain-lain. Penularan penyakit dapat terjadi melalui semua bagian dari tubuh lalat seperti: bulu badan, bulu pada anggota gerak, muntahan serta facesnya (Syamsuddin.et.all 2017).

Selain itu penyebab tingginya ialah kondisi lingkungan fisik (temperatur, kelembaban, sinar dan angin) Lalat mulai aktif beraktifitas pada temperatur $15^{\circ} \mathrm{C}$ dan aktifitas optimunya pada temperatur $21^{\circ} \mathrm{C}$, lalat memerlukan suhu sekitar $35^{\circ} \mathrm{C}-40^{\circ} \mathrm{C}$ untuk beristirahat, dan pada temperatur di bawah $10^{\circ} \mathrm{C}$ lalat tidak aktif dan di atas $45^{\circ} \mathrm{C}$ terjadi kematian pada lalat.

\section{KESIMPULAN}

Berdasarkan hasil penelitian, maka dapat ditarik kesimpulan sebagai berikut :

1. Kepadatan lalat pada saluran pembuangan air limbah (SPAL) termasuk dalam kategori padat dimana rata-rata kepadatan lalat yaitu 17 ekor/blok grill dengan suhu $40,3^{\circ} \mathrm{C}$ kelembaban $50 \%$.

2. Kepadatan lalat pada tempat pembuangan sampah (TPS) termasuk kategoti padat dimana rata-rata kepadatan lalat yaitu 10 ekor/blok grill dengan suhu $33^{\circ} \mathrm{C}$ kelembaban $64 \%$

3. Kepadatan lalat pada sarana air bersih termasuk kategoti padat dimana rata-rata kepadatan lalat yaitu 8 ekor/blok grill $32,3^{\circ} \mathrm{C}$ kelembaban $68 \%$. 
Jurnal Sulolipu : Media Komunikasi Sivitas Akademika dan Masyarakat

Vol. 20 No.12020

e-issn : 2622-6960, p-issn : 0854-624X

\section{SARAN}

Sebaiknya dipelelangan ikan harus menyediakan tempat pembuangan sampah hasil limbah penjualan ikan agar masyarakat tahu akan penyakit yang di timbulkan oleh sampah yang berserakan di sekitar area penjualan ikan. Salah

satu manfaat adanya tempat pembuangan sampah agar mengurangi populasi perkembangbiakan lalat yang bisa menimbulkan penyakit.

\section{DAFTAR PUSTAKA}

Ahamad Annas. 2009. Indonesia Sehat. (http://drannasmaemal.blogspot, diakses 07 April 2014.

Ahmad Hamsir, et.all 2017.ModulPengendalian Vektor dan Binatang Pegganggu. Makassar:Jurusan Kesehatan Republik Indonesia Politeknik Kesehatan Makassar.

Anonim, 2012.Kepadatan Lalat. (Online), (htt://kesling1.blogspot.com, Diakses 20 april 2014.

Badan Pusat Statistik Kota MakassarBps-Statistics Kota Makassar.2015. Kecamatan Makassar Dalam Angka.https://makassarkota.bps.go.id/websiteb/pdf publikasi/Kecamatan-Makassar-DalamAngka-2015.pdf.Diakses 25 Juli 2017.

Devi Nuraini Santi. $2001 . \quad$ Menejemen Pengendalian Lalat, http://repository.usu.ac.id/bitstream/123456789/3497/1/fk-Devi.pdfDiakses 03 Maret 2017.

Eddy, 2008Limbah cair baik domestik maupun non domestik mempunyai beberapa karakteristik sesuai dengan sumbernya.http://jurnalilmiahtp2013.blogspot.co.id/2013/12/limbah-cairdomestik.html,Diakses 25 Februari 2017.

https://www.maxmanroe.com/vid/umun/pengertian sampah.html.diakses tanggal 19 desember 2018.

Juhera, dkk, 2017.Modul Pengelolaan Limbah Cair- A Makassar: Politeknik kesehatan Makassar Jurusan Kesehatan Lingkungan.

Mardana,2007. Definisi Limbah Cair, Limbah cair atau buangan merupakan air yang tidak dapat dimanfaatkan lagi serta dapat menimbulkan dampak yang buruk terhadap manusia dan lingkungan. https://jurnal.usu.ac.id/index.php/lkk/article/defenisi-limbah.html, Diakses 12 maret 2016.

Muntu. Ronny.2016. Penyehatan Air.Makassar : Kementerian kesehatan Republik Indinesia Politeknik Kesehatan Makassar Jurusan Kesehatan Lingkungan.

Republik Indonesia. 2017. Peraturan Menteri Kesehatan Republik Indonesia Nomor 50 Tahun 2017 tentang Standar Baku Mutu Kesehatan Lingkungan dan Persyaratan Kesehatan untuk Vektor dan Binatang Pembawa Penyakit serta Pengendaliannya.

Republik Indonesia.2017.Permenkes RI No.32 tahun 2017 tentang Standar Baku Mutu Kesehatan Lingkungan dan Persyaratan Kesehatan Air Untuk Keperluan Hiegene Sanitasi, Kolam Renang, Solus Per Aqua, dan Permadian Umum.

Sitobang. 2013. PokokTempat Pelelangan Ikan (TPI). prasarana aktivitas nelayan, https://ejournal.unsrat.ac.id/index.php/jurnaleksekutif/article/viewFile/6554/6078. diakses 10 Juli 2014.

Sitohang W. et.all 2013. Hubungan Jarak Kandang dan Pengolahan Limbah Ternak Babi Dan Kepadatan Lalat dalam rumah dengan Kejadian Diare pada Balita di Desa Sabulan Kecamatan Sitiotio Kabupaten Samosir, (online),https://jurnal.usu.ac.id/index.php/lkk/article/view/3289, Diakses 07 Desember 2017.

Sri Elen Husain, et.all Pengaruh Variasi Warna Fly Grill Terhadap Kepadatan Lalat Di Tempat Pelelangan Ikan (TPI) Kota Gorontalo,http://info/33152500-Pengaruh-Variasi-Warna-fly-grillterhadap-kepadatan-lalat-di-tempat-pelelangan-ikan-tpi-kota-Gorontalo.htmIDiakses 24 Februari 2017.

Syamsuddin S. et.all 2017. Pedoman Praktek Pengendalian Vector. Makassar,: Jurusan Kesehatan Lingkungan Politeknik Kesehatan Makassar.

Yunita Kartika Sari.2017, Studi Kualitas Hadis Tentang Lalat. Skripsi.Universitas Islam Negeri Syarif Hidayatullah, Jakarta, htt;//repository.uinikt,ac.id/dspace/bitstream/123456789/37513/2/Y

UNITA \%20KARTIKA\%20SARI-FU.pdf.Diakses Pada Tanggal 22 Desember 2018. 